\title{
Contrahere obligationem en el derecho romano clásico
}

\author{
Adolfo Wegmann Stockebrand*
}

\begin{abstract}
RESUMEN
Este artículo intenta mostrar el error que radica en la equiparación entre el sintagma latino contrahere obligationem y la moderna idea de perfeccionar un contrato, fenómeno que trae consigo la formación de un constructo retrospectivo falso en virtud de la aplicación anacrónica de un concepto dogmático moderno a la experiencia jurídica romana. En el derecho romano clásico, la expresión contrahere obligationem hacía alusión a la actividad lícita concreta desplegada por un agente en orden a engendrar una obligación, es decir, a su causa, la causa obligationum.
\end{abstract}

Contrahere obligationem - obligaciones contractuales - causa de la obligación

\section{Contrahere obligationem in classical roman law}

\begin{abstract}
This paper intends to demonstrate that it is a mistake to equate the Latin syntagm contrahere obligationem to the modern idea of concluding a contract, phenomenon that entails the formation of a false retrospective construction due to the anachronistic use of a modern dogmatic concept applied to the Roman legal experience. In classical Roman law, the phrase contrahere obligationem referred to the lawful and specific activity carried out by an agent in order to give rise to an obligation, meaning, regarding him, the causa obligationum.
\end{abstract}

Contrabere obligationem - contractual obligations - cause of the obligation

* Licenciado en Derecho, Pontificia Universidad Católica de Chile. Doctor en Derecho, Universidad de Heidelberg, Alemania. Profesor de Derecho Romano y Derecho Civil, Pontificia Universidad Católica de Chile. Correo electrónico: aawegman@uc.cl.

Este trabajo se elaboró en el marco del Proyecto Fondecyt Regular No 1170316 "The Systematisation of Roman Law", en el que el autor es coinvestigador.

Artículo recibido el 30 de octubre de 2017 y aceptado para su publicación en este número el 18 de enero de 2019. 


\section{INTRODUCCIÓN}

E 1 sistema de las Pandectas o Digesto, la antología de jurisprudencia clásica promulgada por el emperador bizantino Justiniano el año 533 d.C. como parte principal del Corpus Iuris (Civilis), no es el sistema de la ciencia pandectística ${ }^{1}$. Si bien los textos jurisprudenciales recopilados en el Digesto constituyen la piedra angular de la tradición jurídica europea-continental ${ }^{2}$ y, por tanto, del derecho civil chileno, no ocurre lo mismo respecto de su orden de materias $^{3}$, muy lejano de los criterios sistemáticos de la ciencia jurídica moderna. Lo anterior trae consigo la exigencia metodológica de tomar consciencia de que la atribución de nuestros propios conceptos dogmáticos a la experiencia jurídica romana puede conducir a la formación de constructos retrospectivos falsos, de anacronismos que en nada ayudan a una más profunda comprensión histórica del derecho vigente ${ }^{4}$, que es uno de los objetivos del así llamado comparativismo histórico, esto es, la comparación diacrónica y no solo sincrónica del fenómeno jurídico 5 .

En el presente artículo pretendemos abordar un típico caso de confusión conceptual y consiguiente anacronismo, como es la atribución al sintagma latino contrabere obligationem de un campo semántico equivalente al de celebrar o perfeccionar un contrato, expresión propia de la dogmática moderna y que supone -consciente o inconscientemente- una noción particular de contrato que poco tiene que ver con las obligationes contractae de los antiguos romanos. Nuestro plan de trabajo exige, pues, referirse primeramente a los distintos usos del verbo contrahere en la jurisprudencia romana (I), para luego abordar el problema de la clasificación de las causas de obligación (causae obligationum) en las Instituciones de Gayo y la noción de contrabere obligationem que de ella se desprende (II). Lo anterior nos permitirá contrastar dicha noción con nuestra idea de celebrar o perfeccionar un contrato (III) y extraer de ello conclusiones respecto del derecho contractual romano y su distinción del moderno, así como perspectivas de investigación (IV).

${ }^{1}$ Acerca de esta problemática, la que no puede ser tratada en detalle en esta sede, véase especialmente Brutti, 1979, pp. 317 ss.; Bretone, 1982, p. IX; Cuena Boy, 1998, pp. 16 ss.; Vacca, 2006, p. 30. De la formación del sistema pandectístico, ver por todos SCHWARZ, 1921, pp. 578 ss.

2 De referencia obligada es la obra de WiEACKer, 1967. Una buena y apretada síntesis en lengua española del desarrollo histórico de esta tradición la ofrece CAsınos MorA, 2002, pp. 351 ss.

${ }^{3}$ Según el propio Justiniano (Const. Deo auctore $§ 5$; Const. Tanta/Dedooken $§ 14$ ), el orden de materias del Digesto habría seguido aquel del edicto del pretor urbano, centrado en instrumentos procesales (acciones, excepciones, interdictos, etc.), más que en figuras (por ejemplo, contractuales) desde una perspectiva material. Es importante recordar que la experiencia jurídica romana no conoció la moderna distinción entre derecho material o sustancial y derecho formal. En detalle acerca del desarrollo histórico de esta estructura sistemática Kollmann, 1996, pp. 27 ss.

${ }^{4}$ En relación con el peligro de las construcciones anacrónicas en la investigación histórico-jurídica, en particular respecto de las fuentes romanas, véase especialmente HoEtink, 1955, pp. 39 ss.; NörR, 1994 , pp. 67 ss.; Crifò, 1995, pp. 37 ss.; Avenarius, 2008, pp. 9 ss.

${ }^{5}$ Pertinenete a la naturaleza del comparativismo histórico como método ver en especial WATSON, 1974. Véase también el mismo, 1991, pp. 97 ss.; Gordley, 2006, pp. 754 ss.; LÖHNIG, 2014, pp. 113 ss. 


\section{Horizonte SEMÁNTICO DEL VERBo CONTRAHERE} EN LA JURISPRUDENCIA ROMANA

El primer problema que plantea un estudio del sintagma latino contrabere obligationem en el derecho romano clásico es la circunstancia de que el verbo en cuestión no presenta en nuestras fuentes un sentido unívoco. El verbo latino contrahere es polisémico, esto es, carece de un significado unitario específico, lo que vale no solo para textos literarios ${ }^{6}$, sino que también para aquellos de contenido técnico-jurídico ${ }^{7}$. De ahí que el análisis de su empleo siempre deba ser contextual. En efecto, el vocablo aparece en algunos fragmentos jurisprudenciales referido a situaciones tan lejanas a la idea moderna de "contraer" o "contratar" como pueden ser la destinación de cierta cantidad de grano a un fin determinado ${ }^{8}$, congregar una turba ${ }^{9}$ o reunir cierta cantidad de dinero ${ }^{10}$. Como se puede apreciar, en todos estos casos se trata de un sentido primario de cum-trabere (de donde deriva nuestro verbo), esto es, reunir o aglutinar dos o más cosas ${ }^{11}$.

Incluso podemos encontrar textos en los que contrahere es aplicado a una situación que representa más bien el contrario de contraer o contratar, como es la comisión de un delito. Como se verá más adelante ${ }^{12}$, Gayo presenta en sus Institutiones una clasificación de las obligaciones entre aquellas que nacen de un contrato (obligationes ex contractu) y las que emanan de un delito (obligationes ex delicto) ${ }^{13}$, lo que significa que para el jurista forma parte del primer grupo (contractus) todo acto lícito que genere obligaciones, sin más, ya que solo se le contrapone el hecho ilícito (delictum). Pero ello no impide que el mismo Gayo enseñe, a propósito de su distinción sistemático-didáctica entre cosas corporales e incorporales, que entre estas últimas se encuentran las obligaciones "contraídas" de cualquier manera (obligationes quoquo modo contractae ${ }^{14}$, y una de sus especies consiste, precisamente, en las obligaciones delictuales, como él mismo expone en Gai. 3,88. Igualmente, el Digesto da cuenta del uso del verbo contrahere para describir, por

${ }^{6} \mathrm{El}$ análisis de los distintos usos del verbo contrahere en textos extrajurídicos escapa del objetivo del presente trabajo, por lo que nos remitimos sin más al ya clásico estudio de WunNer, 1964, pp. 10 ss.

${ }^{7}$ Al respecto ver por todos Heumann y Seckel, 1926, p. 105. Para la literatura más reciente nos remitimos principalmente a Melillo, 1994, pp. 125 ss.; GuZmán Brito, 2005, pp. 33 ss. Véase también (para la bibliografía más antigua) BetTi, 1912, pp. 65 ss.; el mismo, 1915, pp. 10 ss.; De FranCisCi, 1916, pp. 213 ss.; Riccobono, 1930, pp. 123 ss.; Lauria, 1938, pp. 165 ss., Voci, 1946, pp. 11 ss.; Grosso, 1963, pp. 29 ss.; WunNer, 1964, pp. 4 ss.; WoŁodKIEWICZ, 1978, pp. 295 ss.

${ }^{8}$ D. $49,5,7$ pr. (Paul. 1.s. de appell.).

${ }^{9}$ D. $47,8,4,6$ (Ulp. 56 ad ed.).

${ }^{10}$ D. 30,96pr. (Iul. 39 dig.).

${ }^{11}$ Heumann y Seckel, 1926, p. 105.

12 Infra, II.

${ }^{13}$ Gai. 3,88: (...) omnis enim obligatio vel ex contractu nascitur vel ex delicto.

${ }^{14}$ Gai. 2,14: Incorporales sunt, quae tangi non possunt, qualia sunt ea, quae in iure consistunt, sicut hereditas ususfructus obligationes quoquo modo contractae (...). Evidentemente, cuando Gayo incluye las obligaciones entre las cosas incorporales, está pensando en el aspecto activo de la relación jurídica, vale decir, en lo que nosotros llamaríamos derecho personal o crédito. Véase Giuffrè, 2016, pp. 108 ss. 
ejemplo, la comisión de delitos en general $^{15}$, de un crimen $^{16}$, de estupro ${ }^{17}$, fraude ${ }^{18}$, o la provocación de un daño ${ }^{19}$. Asimismo, en una constitución imperial de Antonino Caracalla (211-217) se utiliza la formulación contraer un hurto, ciertamente en el sentido de cometer dicho delito ${ }^{20}$. Resulta, pues, evidente, que en las fuentes jurídicas romanas no se encuentra una identificación necesaria entre contrahere y "celebrar un contrato".

Mucho más abundantes son, sin embargo, los casos en los que los juristas romanos emplean el verbo contrahere para aludir a la constitución de una relación jurídica obligatoria a partir de un acto lícito, normalmente -pero debemos recalcar: no exclusivamente- con estructura bilateral, lo que supondría un acuerdo de voluntades ${ }^{21}$. Así encontramos, por ejemplo, los sintagmas contrabere negotium (contraer un negocio) ${ }^{22}$, contrabere stipulationem (contraer una estipulación) ${ }^{23}$, contrabere bypothecam (contraer una hipoteca $)^{24}$, nomina contrahere (adquirir créditos) ${ }^{25}$, o incluso contrahere servitutem para la constitución de una servidumbre ${ }^{26}$. En cambio, la aplicación de este verbo se encuentra excluida del ámbito del derecho de testar (donde reina la unilateralidad) ${ }^{27}$, aunque no por completo del derecho sucesorio 28 .

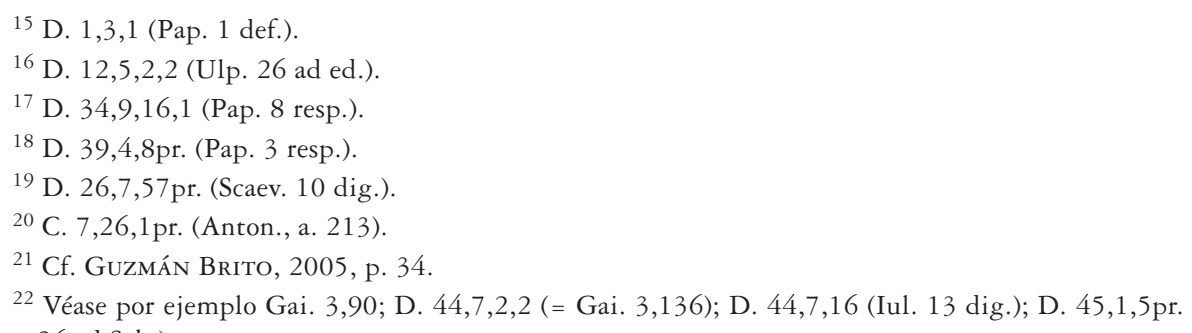
(Pomp. 26 ad Sab.).

23 Por ejemplo D. 40,13,4 (Paul. 12 quaest.).

${ }^{24}$ Por ejemplo D. 20,1,4 (Gai. 1.s. form. hyp.).

${ }^{25}$ Por ejemplo D. 3,5,36,1 (Paul. 1 sent.).

${ }^{26}$ D. 8,3,13pr. (Iav. 10 ex Cass.).

27 Así lo afirma Ulpiano en D. 50,16,20 (Ulp. 12 ad ed.): Verba 'contraxerunt', 'gesserunt' non pertinent ad testandi ius.

${ }^{28}$ Véase D. 42,4,3,3 (Ulp. 59 ad ed.), fragmento en donde pareciera que un pupilo contrae al aceptar una herencia. Matiza esta interpretación de la fuente GUZMÁN BRITO, 2005, p. 35 (n. 40), para quien el uso del verbo contrahere en este caso no se refiere a la aceptación de la herencia considerada en sí misma, sino que al hecho que mediante este acto se contraen créditos, deudas, etc. Sin embargo, debemos tener presente que hay textos de los que se extrae que Ulpiano habría aplicado en ciertos casos, al igual que Gayo (Gai. $3,88)$, una bipartición de las fuentes de las obligaciones, esto es, que todas las obligaciones nacerían de un contrato o de un delito o, lo que es lo mismo, que toda causa de obligación lícita puede ser considerada como contractus. En este sentido D. 5,1,57 (Ulp. $41 \mathrm{ad}$ Sab.): Tam ex contractibus quam ex delictis in filium familias competit actio (...). Así ocurre también en D. 13,5,1,6 (Ulp. 27 ad ed.) y D. 50,17,23 (Ulp. 29 ad Sab.) en materia de tutela, en D. 13,6,5,2 (Ulp. 28 ad ed.) respecto de la constitución de la dote (que puede tener lugar por medio de una promesa unilateral: uno loquente, nulla praecedente interrogatione, como enseña Gayo en Gai. 3,95a), o nuevamente en D. 50,17,23 (Ulp. 29 ad Sab.) para la gestión de negocios ajenos. En este orden de cosas, bien podría afirmarse que Ulpiano califica la aceptación de la herencia propiamente tal como contrato, en la medida que, evidentemente, no se trata de un hecho ilícito. 
De esta guisa, en el lenguaje jurídico el verbo contrabere suele ser utilizado en un sentido más bien restringido, identificable con la constitución de una relación obligatoria por medio de un acto lícito, en muchos casos (no necesariamente) de estructura bilateral (basada en una convención), aunque ello no siempre sea así, como demuestran los ejemplos recién enunciados de uso del vocablo para aludir a la comisión de hechos ilícitos, los que mal podrían suponer un acuerdo entre su autor y la víctima de los mismos. Con todo, a la luz de los testimonios conservados en las fuentes, la vinculación entre contrahere y delictum es claramente excepcional; la etimología cum-trabere no tiene tanto el sentido de traer o producir conjuntamente, sino más bien el de generar, en una relación con otro sujeto y, por tanto, dentro de los márgenes de la licitud, determinados efectos, los que pueden ser tanto queridos por las personas implicadas como no deseados; vale decir, sin que se requiera necesariamente una convención ${ }^{29}$.

En síntesis, contrabere aparece en las fuentes jurídicas romanas más bien con el sentido de la creación de una relación jurídica obligacional entre dos o más personas por medio de un acto lícito ${ }^{30}$, lo que supone, en definitiva, un vínculo objetivo entre distintos patrimonios ${ }^{31}$. Como señala Guzmán Brito, “(...) el verbo contrabere prácticamente carece de todo tecnicismo específico y que en general es utilizable para describir cualquier actuación bilateral para indicar bien la celebración del acto, bien su resultado, es decir, la relación generada misma" 32 . Dicho en otros términos: el sentido jurídico del verbo contrahere consiste esencialmente en dar nacimiento a una relación jurídica mediante un acto conforme a derecho.

Ahora bien, de todas las aplicaciones del sintagma latino contrabere obligationem, la que sin duda tuvo mayor relevancia en el derecho romano clásico y ha tenido mayor influencia en el desarrollo de la tradición jurídica de los siglos posteriores, es aquella relativa a la clasificación de las relaciones de naturaleza contractual (vale decir: lícitas) en cuatro categorías, a saber, obligaciones contraídas por medio de una cosa, de las palabras, de la escritura o del consenso: obligationes re, verbis, litteris y consensu contractae, como se expresa en Gai. 3,8933. Es, precisamente, una -a nuestro juicio- anacrónica comprensión de este fragmento, lo que ha llevado a los intérpretes a ver aquí una asimilación entre contraer una obligación en su sentido genuinamente romano, y perfeccionar un contrato, así como se entiende esta expresión en la dogmática moderna.

${ }^{29}$ Cf. Melillo, 1994, p. 127.

${ }^{30}$ El contractus de Gai. 3,88, contrapuesto solo al delictum.

${ }^{31}$ En este sentido ya BETTI, 1912, p. 68 (n. 3), hablaba en general de un "rapporto di obbligazione"; el mismo, 1915, p. 62, se expresaba en términos de una "relazione obbiettiva di due individualità patrimoniali distinte”. Véase también Lauria, 1938, p. 172, 179 ss.; Schiavone, 1971, p. 160; WoŁodkiewiCz, 1978, p. 298; COMA Fort, 1996, p. 147 (n. 350); Jörs, Kunkel, y Wenger, 1949, p. 187 (n. 1). En este contexto, Melillo, 1994, cit., p. 130, se refiere al negotium contractum como un "affare portato a compimento insieme", un "fenomeno di cooperazione attiva".

32 GuZmán Brito, 2005, p. 35.

${ }^{33}$ Gai. 3,89: (...) aut enim re contrabitur obligatio aut verbis aut litteris aut consensu. Sobre la fuente vid. infra, II. 
Es, pues, en este contexto donde se presenta el problema del auténtico significado del sintagma contrabere obligationem en derecho romano clásico.

\section{CONTRAHERE OBLIGATIONEM Y CAUSAE OBLIGATIONUM EN LAS INSTITUCIONES DE GAYO}

Dos textos permiten ilustrar adecuadamente el significado del sintagma contrabere obligationem en el pensamiento de Gayo y, consecuencialmente, de la cuatripartición de las obligaciones contractuales (obligationes contractae) en reales (re), verbales (verbis), literales (litteris) y consensuales (consensu). La primera de ellas contiene la -ya mencionada- célebre bipartición de las obligaciones en contractuales y delictuales, en los siguientes términos:

Gai. 3,88: Nunc transeamus ad obligationes. Quarum summa divisio in duas species diducitur: omnis enim obligatio vel ex contractu nascitur vel ex delicto. ["Pasemos ahora a las obligaciones, cuya suprema división establece dos especies: toda obligación nace de un contrato o de un delito" $]^{34}$.

Como se puede apreciar de la lectura del texto transcrito, Gayo presenta aquí la que, a su juicio, es la clasificación de las obligaciones más amplia de todas: su summa divisio. En efecto, para él no hay más especies de obligación que aquellas nacidas de contrato o de delito, excluyendo toda otra posibilidad, lo que se deduce con claridad del uso de la expresión "toda obligación" 35 . No hay, pues, un tertium quid entre una y otra causa de obligación. Consecuentemente, el jurista aplica la misma divisio a las actiones in personam, lo que no debe extrañar, si se tiene presente que obligatio y actio no son sino dos caras de la misma moneda: acción personal es aquella con la que litigamos con alguien que está obligado respecto de nosotros en virtud de contrato o de delito ${ }^{36}$.

Por consiguiente, y dejando al margen la cuestión muy debatida -pero que no corresponde tratar en esta sede- acerca de qué causa de obligación es más antigua, si el contrato o el delito ${ }^{37}$, lo cierto es que en Gai. 3,88 y 4,2 se expone una noción amplísima de contrato, elaborada única y exclusivamente sobre la base de su contraposición al delito (lo que no implica necesariamente que este sea más antiguo que aquel), lo que significa que toda causa de obligación que no sea constitutiva de un hecho ilícito

${ }^{34}$ Cf. Gai. 4,112-113, donde vuelve a presentarse la bipartición entre acciones ex maleficio $(4,112)$ y ex contractu (4,113). Maleficium es, en el lenguaje gayano, sinónimo de delictum.

35 En este sentido ya Pernice, 1888, pp. 196 ss. Véase también Segrè, 1952, pp. 433 ss.; Lauria, 1938, pp. 163 ss., 172; Schulz, 1951, pp. 466 ss.; Grosso, 1963, pp. 3 ss.; Wunner, 1964, pp. 42 ss. Para la bibliografía más reciente ver por ejemplo PARICio, 1994, pp. 49 ss.; el mismo, 1997, pp. 151 ss., 153; el mismo, 2008, pp. 28 ss.; Cannata, 2008, pp. 82 ss.

${ }^{36}$ Gai. 4,2: In personam actio est, qua agimus cum aliquo qui nobis vel ex contractu vel ex delicto obligatus est (...). Cf. D. 44,7,25,1 (Ulp. 1.s. reg.).

${ }^{37}$ Para el debate científico respecto de esta cuestión véase por ejemplo TalamanCA, 1979, pp. 2 ss.; Betti, 1955, pp. 97 ss., 102 ss.; Kaser, 1949, pp. 188 ss.; De Visscher, 1931, pp. 342 ss. 
(delictum), representa un contractus. En otros términos: la idea de contrato contenida en las Instituciones de Gayo se identifica con todo hecho lícito del que nacen obligaciones ${ }^{38}$. Tal noción de contrato la podemos encontrar también en fragmentos de la jurisprudencia tardoclásica, específicamente de Ulpiano ${ }^{39}$ y Paulo ${ }^{40}$.

Inmediatamente después de presentar su dicotomía obligationes ex contractu-obligationes ex delicto, Gayo clasifica las primeras en cuatro géneros, como sigue:

\begin{abstract}
Gai. 3,89: Et prius videamus de his, quae ex contractu nascuntur. harum autem quattuor genera sunt: aut enim re contrabitur obligatio aut verbis aut litteris aut consensu. ["Y veamos primero acerca de las <obligaciones > que nacen de un contrato. De estas hay cuatro géneros: se contrae una obligación por la cosa, por palabras, por la escritura o por consenso" $]^{41}$.
\end{abstract}

La fuente citada constituye la base de la tradicional clasificación de las obligationes contractae romanas en cuatro categorías. Específicamente, Gayo plantea que las obligaciones ex contractu (no los contratos; nótese la diferencia) pueden nacer (se contraen) en virtud de la transferencia del dominio de una cosa (re contrabere) ${ }^{42}$, de una promesa formal verbal (verbis contrahere) ${ }^{43}$, de la anotación de un traspaso ficticio de dinero en el libro de cuentas del acreedor (codex accepti et expensi) con la aprobación del deudor (litteris contrabere) ${ }^{44}$ o del acuerdo de voluntades entre las partes (consensu contrabere) ${ }^{45}$. Se suele afirmar que el criterio empleado por Gayo para clasificarlas de esta forma habría sido el modo de perfeccionamiento de cada figura. Así, por ejemplo, la transferencia del dominio sobre una cosa (datio rei, de donde deriva la aplicación en la especie del

38 Así ya Schulz, 1951, p. 466: "Obviously this is a classification of all possible obligations; consequently contractus must need embrance any legal act from which obligations resulted, delicts alone being excluded”. En el mismo sentido, más recientemente PARICIO, 2008, p. 34: “Así pues, aunque Gayo no incluya una definición de contrato, parece claro que tiende a configurarlo como una categoría donde se engloban todos los actos lícitos reconocidos por el ius civile, convencionales o no convencionales, destinados a crear un vínculo obligatorio, al margen del cual, y como contrapuesto a él, queda el ámbito de los delitos". Cf. también, sobre la noción gayana de contrato, no fundada en el consensus, el mismo, 1997, pp. 151 ss.; SARGenti, 1988, pp. 24 ss., 56; Martini, 1991, pp. 97 ss.; Wegmann STOCKebrand, 2017b, pp. 333 ss.

39 Por ejemplo en D. 5,1,57 (Ulp. 41 ad Sab.): Tam ex contractibus quam ex delictis in filium familias competit actio (...), y los demás textos citados en n. 28.

${ }^{40}$ Por ejemplo en D. 5,3,14 (Paul. 20 ad ed.): Sed utrum ex delicto an ex contractu debitor sit, nibil refert (...).

${ }^{41}$ Véase también Gai. 3,119a, donde el jurista reitera que las obligaciones pueden contraerse re, verbis, litteris o consensu, a propósito de las relaciones obligatorias que pueden garantizarse por medio de la fideiussio (fianza): Fideiussor vero omnibus obligationibus, id est sive re sive verbis sive litteris sive consensu contractae fuerint obligationes, adici potest (...).

42 Específicamente la mutui datio; Gai. 3,90. En detalle sobre la limitación del re contrabere a la mutui datio en el derecho romano clásico Wegmann STOckebrand, 2017a, pp. 115 ss.

43 Esto es, la sponsio/stipulatio y la dotis dictio; Gai. 3,92 ss.

${ }^{44}$ Se trata de la expensilatio o nomen transscripticium; Gai. 3,128 ss.

${ }^{45}$ En concreto, la compraventa (emptio venditio), el arrendamiento (locatio conductio), la sociedad (societas) y el mandato (mandatum); Gai. 3,135 ss. A ello se puede agregar la hipoteca (conventio pignoris), como aparece, por ejemplo, en D. 22,4,4 (Gai. l.s. form. hyp.). 
ablativo re) constituiría el modo de perfeccionar la obligatio re contracta y, por tanto, el "contrato real".

Discrepamos de esta opinión. Si como hemos visto, contrabere no expresa necesariamente -como el jurista formado en la dogmática moderna tendería a creer casi espontáneamente- el perfeccionamiento o la celebración de un contrato, sino que aparece en las fuentes jurídicas romanas en un sentido más amplio, identificable más bien -dejando de lado por un momento su excepcional empleo respecto de la comisión de hechos ilícitos- con la constitución de una relación obligatoria por medio de un acto lícito, lo dicho trae consigo una consecuencia de capital importancia para nuestra comprensión del sentido que Gayo quiso darle al sintagma contrahere obligationem en sus cuatro géneros arriba enunciados.

A nuestro entender, la estructura dialéctica de la clasificación de las obligationes en general y de las obligationes contractae en especial, contenida las Instituciones de Gayo, obedece a un criterio causal: Gayo distingue entre obligationes re, verbis, litteris y consensu contractae no en consideración al modo como se perfeccionaría un supuesto contrato real, verbal, literal o consensual (terminología que se aleja muchísimo de la utilizada por el maestro de época antonina), sino que al fundamento, la causa de la que procede, respectivamente, cada género de obligación contractual. En sus Institutiones, Gayo recurre al empleo de la partícula ex en la summa divisio de las obligaciones entre contractuales y delictuales (ex contractu-ex delicto; Gai. 3,88), o bien, la forma ablativa, sin preposición, para la consiguiente cuatripartición de las primeras (re, verbis, litteris und consensu contrabere; Gai. 3,89). Se trata de dos modos de expresar lo mismo en una lengua que, usada elegantemente, es más amiga de las declinaciones que de las preposiciones. Así, la variación morfológica de los sustantivos res (cosa), verbum (palabra), littera (letra) y consensus (consentimiento), de su forma en nominativo a, respectivamente, re (por medio, a través, por causa de una cosa), verbis (por medio, a través, por causa de las palabras), litteris (por medio, a través, por causa de las letras/de la escritura) y consensu (por medio, a través, por causa del consentimiento) expresa gramaticalmente sin lugar a dudas un vínculo causal entre estos elementos y la obligación que nace: esta es constituida por medio, a través o por causa de una cosa, de las palabras, de la escritura o del consentimiento: re contrabitur obligatio aut verbis aut litteris aut consens $u^{46}$.

Cuando se analizan los pasajes de las Instituciones de Gayo en donde se recurre al sintagma contrabere obligationem, se obtiene como resultado que en estos siempre se hace alusión a los comportamientos concretos, las acciones materiales que traen consigo el nacimiento de una relación obligatoria, no al "perfeccionamiento" de un contrato ${ }^{47}$. Un claro ejemplo de lo dicho es el siguiente:

\footnotetext{
${ }^{46}$ Véase también Gai. 2,81; 2,82; 3,96; 3,124; 3,136; 3,138; 3,155; 3,157.

${ }^{47}$ Cf. Falcone, 2011, pp. 17 ss.
} 
Gai. 2,81: Ideoque si quando mulier mutuam pecuniam alicui sine tutoris auctoritate dederit, quia facit eam accipientis, cum scilicet pecunia res nec mancipi sit, contrabit obligationem. ["Por eso, si una mujer prestare alguna vez dinero a alguien sin la autorización de su tutor, como hace que dicho dinero pase a ser propiedad de quien lo recibe, este contrae una obligación, puesto que el dinero es una cosa no mancipable”].

El texto citado trata de un préstamo de dinero efectuado por una mujer sin la autorización de su tutor, en virtud de ello el adquirente del mismo - dice el jurista-contrae una obligación (contrabit obligationem) de restitución ${ }^{48}$. El trasfondo del fragmento es, ciertamente, el problema de la posición jurídica de la mujer en Roma, en particular, su capacidad para transferir el dominio de ciertos bienes o para celebrar actos y contratos. En lo que importa para efectos de comprender el contexto sociocultural de esta fuente, baste decir que la mujer sui iuris, esto es, no sometida a la patria potestas de su padre ni a la manus (potestad marital) de su marido y, por tanto, en principio plenamente capaz, quedaba sujeta -salvo contadas excepciones- a tutela por toda la vida ${ }^{49}$.

En este orden de cosas, las mujeres requerían la autorización de su tutor para enajenar los así llamados bienes mancipables (res mancipi), que constituían un catálogo breve y cerrado de cosas de especial valor (res pretiosiores) ${ }^{50}$ para la economía romana más arcaica, esencialmente agropecuaria: fundos itálicos, servidumbres rústicas, esclavos y animales de tiro y carga que se doman por el cuello o el lomo (en concreto: caballos, mulas, asnos y bueyes $)^{51}$. Asimismo, dicha enajenación solo podía tener lugar por medio de dos modos solemnísimos para adquirir el dominio. Uno era la mancipatio (de donde deriva la denominación de estas cosas), negocio abstracto cuya estructura exigía la participación de nada menos que ocho personas: la parte que transfiere el dominio (mancipio dans), quien lo adquiere (mancipio accipiens), un libripens (encargado de la balanza con la que, simbólicamente, se pesaba el dinero con el que el adquirente pagaba el valor de la cosa objeto del negocio) y cinco testigos púberes y ciudadanos romanos. El otro, más bien excepcional, era la in iure cessio, que consistía esencialmente en un juicio de vindicación simulado ante el magistrado ${ }^{52}$. En cambio, para la transferencia de la propiedad sobre cualquier otro bien no mancipable (res nec mancipi), la mujer sui iuris no requería la autorización de su tutor, por lo que podía actuar válidamente por sí sola ${ }^{53}$.

A esta última clase de cosas pertenece, precisamente, el dinero (pecunia). El fragmento se refiere, pues, al fundamento de la obligación de restitución del adquirente de una determinada cantidad de dinero recibida en préstamo de parte de una mujer que

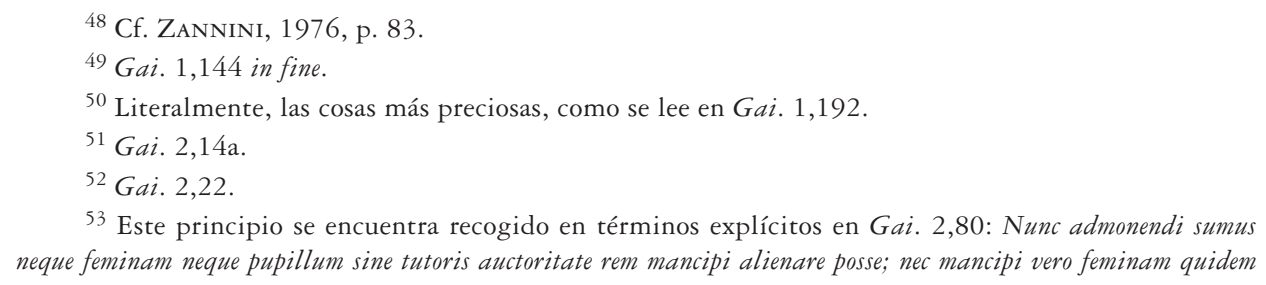

53 Este principio se encuentra recogido en términos explícitos en Gai. 2,80: Nunc admonendi sumus neque feminam neque pupillum sine tutoris auctoritate rem mancipi alienare posse; nec mancipi vero feminam quidem posse, pupillum non posse. 
ha obrado sine tutoris auctoritate. En la especie, el dinero ha sido dado en mutuo, esto es, credendi causa, a título de crédito ${ }^{54}$. A esto alude Gayo cuando emplea los términos mutuam pecuniam... dederit: la mujer ha efectuado una datio rei, concretamente una mutui datio, y esta ha hecho al adquirente dueño de la cantidad de dinero recibida (quia facit eam accipientis), quien a su vez ha contraído la obligación de restituirla en un momento posterior (contrabit obligationem). Gayo en ningún momento se refiere directamente a la celebración o perfeccionamiento de un contrato de mutuo; el jurista se refiere a la dación mutuaria (datio mutui) desde una perspectiva, por así decirlo, material, en el sentido de la actividad concreta desplegada por la mujer, más que a la celebración de un contrato de mutuo. Nótese que, en efecto, en el texto se recurre al verbo contrabere no en relación con el contrato mismo, sino que específicamente a la obligación a la que se encuentra sujeto el adquirente. El fundamento, la causa de la obligación de restitución "contraída" por el accipiens radica en que este se ha convertido en propietario del dinero recibido de parte de la mujer (quia facit eam accipientis), la que no se ha limitado a entregar una cierta cantidad de dinero, sino que ha transferido el dominio sobre él, y la razón de ello estriba en que, como se ha dicho, la pecunia constituye una res nec mancipi, que en cuanto tal puede ser transferida por una mujer sine tutoris auctoritate.

En el texto comentado, el perfeccionamiento de un contrato de mutuo no desempeña ningún papel relevante para efectos de determinar que se ha contraído una obligación.De hecho, en el así llamado Ulpiani Epitome (11,27), una obra pseudoulpianea que depende en gran medida de las Instituciones de Gayo, o bien, de una tradición escolar común a Gayo, se formula la regla consistente en que las mujeres requieren la autorización de su tutor tanto para concluir un negocio jurídico como para enajenar cosas mancipables ${ }^{55}$. Si se analiza este último texto en relación con Gai. 2,81, bien puede concluirse que en un caso como el expuesto por Gayo, el contrato de mutuo habría sido inválido; no obstante ello, y esto es lo que nos interesa, el accipiens ha "contraído" la obligación de restituir el dinero recibido credendi causa, a título de crédito, porque la mujer estaba facultada para transferir el dominio del mismo en cuanto res nec mancipi. Dicho en otros términos: Si bien la suscripción de un contrato de mutuo por una mujer sin la autorización de su tutor no es válida, de todos modos el adquirente del dinero contrae una obligación, ya que esta no encuentra su causa en el perfeccionamiento del contrato, lo que sería una abstracción muy poco romana, sino que directamente en la datio rei, la transferencia del dominio. De lo anterior se colige, pues, que el sintagma contrabere obligationem presente en este fragmento se refiere de una manera muy concreta a la actividad desplegada por la mujer que hace nacer la obligación de restitución del accipiens, esto es, a la datio, mas

${ }^{54}$ D. 12,1,2,1 (Paul. 28 ad ed.): Mutui datio consistit in his rebus, quae pondere numero mensura consistunt, quoniam eorum datione possumus in creditum ire (...). Cf. D. 12,1,1,1 (Ulp. 26 ad ed.), donde Ulpiano expone la noción de causa crediticia contenida en el edicto del pretor: (...) nam cuicumque rei adsentiamur alienam fidem secuti mox recepturi quid, ex hoc contractu credere dicimur (...).

55 UE 11,27: Tutoris auctoritas necessaria est mulieribus quidem in his rebus (...) si civile negotium gerant (...) si rem mancipi alienent (...). Cf. UE 11,18. A este respecto véase AvEnARIUs, 2005, pp. 311 ss.; para la mutui datio GrösCHLER, 1997, pp. 194 ss. 
no en términos abstractos a la celebración de un contrato, cuestión respecto de la que Gayo nada dice.

En términos similares expone el jurista el caso del pupilo que, sin la autorización de su tutor, entrega una cierta cantidad de dinero a título de crédito.

Gai. 2,82: At si pupillus idem fecerit, quia non facit accipientis sine tutoris auctoritate pecuniam, nullam contrabit obligationem: unde pupillus uindicare quidem nummos suos potest, sicubi extent, id est eos petere suos ex iure Quiritium esse [....vv. 5....]. ["Pero si un pupilo hiciere lo mismo, puesto que sin la autorización de su tutor no hace que el dinero pase a ser propiedad de quien lo recibe, este no contrae ninguna obligación; de ahí que el pupilo pueda ciertamente vindicar sus propias monedas, donde quiera que permanezcan, esto es, considerarlas como suyas por derecho de los Quirites (...)" $]^{56}$.

En la antigua Roma, los impúberes (niños mayores de catorce años, niñas mayores de doce) sui iuris, vale decir, no sometidos a patria potestas (generalmente debido a la muerte de su padre), quedaban sujetos a tutela. En lo que respecta a su capacidad para transferir el dominio, nuestras fuentes son muy claras: el pupillus no puede transferir sin autorización de su tutor ninguna clase de bienes, sin importar si estos son mancipi o nec mancipi ${ }^{57}$. Como expresa lacónicamente Gayo en su comentario al edicto del pretor provincial: nullum dominium transferre potest ${ }^{58}$. En cambio, sí se encuentra facultado para adquirir la propiedad por sí mismo, en virtud del principio de que incluso sine tutoris auctoritate puede mejorar su situación jurídica (meliorem condicionem suam facere), al igual que la mujer ${ }^{59}$. Pues bien, a causa de que el pupilo no puede transferir la propiedad en absoluto sin interpositio auctoritatis, no le es posible constituir una obligación real (obligatio re contracta), ya que esta supone necesariamente una datio rei. Es por ello que, para este caso, Gayo enseña que la cantidad de dinero entregada por el pupilo a un tercero en préstamo no implica que este último "contraiga" una obligación restitutoria credendi causa (nullam contrabit obligationem), toda vez que no se ha hecho dueño del dinero (quia non facit accipientis suam pecuniam $)^{60}$. Consecuencialmente, a juicio del jurista, el pupilo carece de legitimación activa para ejercer la condictio (acción personal restitutoria), ya que esta supone una datio rei, no quedándole otra alternativa más que vindicar la pecunia, porque sigue siendo dueño y el tercero adquirente es, en realidad, solo un poseedor. Como puede apreciarse, aquí Gayo, al igual que en el fragmento anterior, se concentra en

\footnotetext{
${ }^{56}$ El fragmento citado solo se ha conservado parcialmente, no siendo posible una reconstrucción segura del mismo a continuación de id est. Para los distintos intentos de reconstrucción de la parte faltante del texto véase por todos David y Nelson, 1954, pp. 294 ss.

${ }^{57}$ Gai. 2,80; 2,84; UE 11,27; I. 2,8,2. Véase también 12,1,19,1 (Iul. 10 dig.); D. 14,6,3,2 (Ulp. 29 ad ed.); D. 46,3,14,8 (Ulp. 30 ad Sab.). Cf. Labruna, 1962, pp. 90 ss.; Kaser, 1961, pp. 208 ss.

${ }^{58}$ D. 26,8,9,2 (Gai. 12 ad ed. prov.).

59 Gai. 2,83: Et ex contrario omnes res tam mancipi quam nec mancipi mulieribus et pupillis sine tutoris auctoritate solui possunt, quoniam meliorem condicionem suam facere eis etiam sine tutoris auctoritate concessum est.

${ }^{60}$ Cf. D. 12,1,2,2 (Paul. 28 ad ed.): Appellata est autem mutui datio ab eo, quod de meo tuum fit: et ideo, si non faciat tuum, non nascitur obligatio.
} 
la actividad desplegada por el pupilo, que puede o no ser la causa de que el adquirente "contraiga" una obligación, mas no en el supuesto perfeccionamiento de un contrato, el que igualmente debiera ser considerado inválido ${ }^{61}$.

A partir de lo anterior podemos extraer la siguiente conclusión: respecto de la clasificación de las obligaciones ex contractu, la transferencia del dominio de una cosa (re contrabere), la promesa formal verbal (verbis contrabere), la anotación en el libro de cuentas del acreedor con la aprobación del deudor (litteris contrabere) y el acuerdo de voluntades entre las partes (consensu contrabere), constituyen las posibles "causas" lícitas de obligación en un sentido muy concreto, vale decir, la actividad desplegada por un agente que provoca que otra persona quede obligada respecto de ella, no en abstracto como los modos en los que se perfeccionaría una determinada figura contractual ${ }^{62}$. Como acertadamente expresa Falcone, no debe sorprendernos que Gayo, en vez de describir en términos abstractos en qué consiste una obligación contractual, haya abordado directamente la cuestión de las causas que dan lugar a una relación obligatoria, entendidas estas como los comportamientos concretos de un sujeto de los que puede nacer una obligatio ${ }^{63}$. De ahí que planteemos la tesis de que, si queremos ser fieles al testimonio de nuestras fuentes, en el pensamiento gayano el sintagma contrabere obligationem no debe ser identificado con el perfeccionamiento de un contrato, sino con el nacimiento, la causación de una obligación mediante un acto lícito, cuya tipología puede ser resumida en cuatro "causas": res (datio rei), verba, litterae y consensus.

\section{CAUSA OBLIGATIONUM VERSUS PERFECCIONAMIENTO DEL CONTRATO}

Ciertamente, lo que decimos dista mucho de representar la opinión mayoritaria. En doctrina tiende a primar una idea de la obligatio contracta romana que, consciente o inconscientemente, está notoriamente influenciada por la moderna noción del contrato como convención, que tiene sus antecedentes más remotos en algunas fuentes antiguas ${ }^{64}$ y, especialmente, en la Paráfrasis de Teófilo a las Instituciones de Justiniano (esto es, en el

61 Véase LONGO, 1933, pp. 26 ss.; Viard, 1939, pp. 52 ss.; KASER, 1961, pp. 211 ss.; LABrunA, 1962, pp. 90 ss.; ZanNini, 1976, pp. 82 ss.

${ }^{62}$ Lo dicho encuentra sustento también en otros fragmentos gayanos. Así, por ejemplo, se habla en términos explícitos de causa de obligación en Gai. 3,96. Por su parte, en Gai. 3,124, el obligationem contrabere se refiere específicamente a una datio pecuniae (como en Gai. 2,81), no a la celebración de un contrato de mutuo.

${ }^{63}$ FALCONE, 2011, p. 30: “(...) non sorprende che Gaio, anziché indugiare su un enunciato che descriva in termini astratti cosa è un obligatio, abbia direttamente affrontato, sul piano dei concreti comportamenti dei soggetti agenti, le causae che danno vita ad un'obligatio". Cf. PerniCe, 1888, p. 222; Perozzi, 1898, pp. 163 ss.; Brasiello, 1930, pp. 541 ss.; el mismo, 1944, pp. 101 ss.; Voci, 1946, p. 70; KaSer, 1971, p. 522; Dalla Massara, 2004, pp. 351 ss. para la obligatio re contracta.

${ }^{64}$ Fundamentalmente D. 2,14,1,3 (Ulp. 4 ad ed.): (...) ut eleganter dicat Pedius nullum esse contractum, nullam obligationem, quae non habeat in se conventionem (...). Acerca de la fuente véase por todos Garofalo, 2006, pp. 337 ss. 
derecho bizantino $)^{65}$, pero que jamás llegó a consolidarse como doctrina indiscutida en la jurisprudencia clásica ${ }^{66}$. Esta perspectiva parte del supuesto de que todo contrato sería esencialmente una convención (conventio) y que el consentimiento de las partes se manifestaría de distintas maneras, lo que sería la raíz de la cuatripartición. Vale decir, el consentimiento se expresaría, según el caso, mediante la transferencia del dominio de una cosa ( $r e$ ), de una promesa formal verbal (verbis), de la anotación en el codex accepti et expensi del acreedor con la aprobación del deudor (litteris), o bien, del simple acuerdo de voluntades entre las partes exento de formalidades (consensu).

La distinción que hacemos podrá parecer a alguien una mera sutileza lingüística, pero lejos de aquello, es de gran relevancia histórico-dogmática. La atribución al re, verbis y litteris contrahere del carácter de modos especiales de manifestación de la voluntad trae consigo que sean considerados como una suerte de complementos del consenso, en el sentido que todo contrato constituiría básicamente un acuerdo de voluntades que, en ciertos casos, el ordenamiento jurídico exigiría que se exprese bajo formas determinadas, en orden a que el contrato en cuestión sea concluido (perfeccionado) válidamente. Dicho en otros términos: todo contrato es una convención, pero no siempre será suficiente el "mero consenso" para perfeccionarlo ${ }^{67}$. Así, por ejemplo, el contrato real, para ser perfecto, requerirá, además del mero consentimiento, la entrega de la cosa. Esta es, de hecho, la idea que subyace al artículo 1.443 de nuestro Código Civil ${ }^{68}$. Bajo esta premisa, muy lejana al pensamiento gayano, es posible construir “categorías contractuales” tal y como las entiende la dogmática moderna, esto es, en función del modo como se perfeccionan los distintos tipos contractuales, todos estos presentan un elemento unificador, a saber, la convención ${ }^{69}$. El criterio ordenador de las obligationes ex contractu en la jurisprudencia clásica, en cambio, era otro: el comportamiento concreto desplegado por un sujeto en orden a engendrar una obligación, sin que se presente un elemento unificador más allá de la mera licitud de la causa obligationis, que permite distinguir la obligatio ex contractu de la ex delicto (Gai. 3,88).

En síntesis: para el derecho romano clásico, el res, verbis, litteris y consensu contrabere constituían las actividades lícitas, independientes entre sí, que el ordenamiento jurídico romano reconocía como habilitadas para dar nacimiento a una obligatio ex contractu y, consecuencialmente, a una actio típica (Gai. 4,2). Nada, pues, de modos especiales de

${ }^{65}$ PT 3,13,2. La identificación bizantina entre contrato y convención deriva de la noción de pacto contenida en D. 2,14,1,2 (Ulp. 4 ad ed.): Et est pactio duorum pluriumve in idem placitum et consensus.

${ }^{66}$ A juicio de SARgenti, 1988, p. 73, ni siquiera en época justinianea.

${ }^{67}$ Cf. Harke, 2016, p. 44.

68 "El contrato es real cuando, para que sea perfecto, es necesaria la tradición de la cosa a que se refiere; es solemne cuando está sujeto a la observancia de ciertas formalidades especiales, de manera que sin ellas no produce ningún efecto civil; y es consensual cuando se perfecciona por el solo consentimiento”. Más explícito aún era el artículo $6^{\circ}$ de la parte del Proyecto de Código Civil correspondiente al Libro de los contratos y obligaciones convencionales; título I (definiciones): "El contrato es real cuando, además del consentimiento, se exige, para que sea perfecto, la tradición de la cosa a que se refiere el contrato; i consensual cuando se perfecciona por el solo consentimiento".

${ }^{69}$ Cf. Orestano, 1959, pp. 455 ss., respecto de la estructura genus-species de Gai. 3,88 ss. 
manifestar la voluntad o casos particulares de perfeccionamiento de figuras contractuales, que no eran algo que interesara mayormente a los clásicos. Como acertadamente afirma Brasiello, basar la cuatripartición de las obligaciones contractuales en un elemento perfeccionador no se condice con los criterios clasificatorios empleados por la jurisprudencia clásica, mientras que sí servía a los fines sistemático-didácticos de los juristas bizantinos, quienes, considerando todos los contratos como esencialmente consensuales, querían de todos modos encuadrarlos en los esquemas clásicos precedentes ${ }^{70}$.

Una vez más, el esquema dialéctico empleado por Gayo da pistas de lo dicho. En efecto, como hemos visto, el maestro antonino clasifica las obligaciones ex contractu en cuatro géneros (quattuor genera sunt), reiterando la misma idea luego, en Gai. 3,182 (in IIII genera diducantur). En cambio, y he aquí la clave, los delitos no se clasificarían en géneros, ya que todos forman parte del mismo (quarum omnium rerum uno genere consistit obligatio $)^{71}$. No bastando con eso, Gayo vuelve a explicitar esta diferencia en sus res cottidianae $^{72}$. Es admisible destacar que el jurista se esmera en resaltar esta diferencia, afirmando que a diferencia (alioquin) de las obligaciones contractuales, que se subdividen en géneros, todos los delitos constituyen un solo género. De acuerdo con este esquema, las obligationes ex contractu se caracterizan por presentar cuatro posibles causas que son esencialmente distintas e incompatibles entre sí, de modo que no se encuentra en los distintos contratos un fundamento unificador más allá de la licitud del acto que lo hizo nacer. Esta es la consecuencia de calificar a las obligationes re, verbis, litteris y consensu contractae como "géneros". De esta guisa, los así llamados contratos reales, verbales, literales y consensuales de los antiguos romanos no son los elementos de un, por así decirlo, sistema contractual romano unificado, sino más bien fenómenos esencialmente distintos los unos de los otros. Así, siguiendo a Harke, incluso podría llegar a sostenerse la existencia de distintos "sistemas contractuales" en el derecho romano clásico, uno para cada género de obligatio ex contractu ${ }^{73}$.

Será tarea de los juristas de época justinianea, quienes identificaban al contrato con la convención sin más (PT 3,13,2), buscar la manera de encuadrar el esquema dialéctico clásico con su nueva teoría contractual; y la fórmula que encontrarán será convertir los quattuor genera gayanos en las quattuor species de las Instituciones de Justiniano ${ }^{74}$. Esto es,

${ }^{70}$ Brasiello, 1944, pp. 103: "Il fondare infatti la partizione sull'elemento perfezionatore, come apparirà anche in questo studio, non può essere frutto che di uno sforzo che i giuristi classici non avrebbero motivo di fare, mentre si impone -e, come vedremo, nemmeno sempre-ai compilatori, i quali, pure considerando tutti i contratti come consensuali, volevano ancora inquadrarli negli schemi classici”.

${ }^{71}$ Gai. 3,182: Transeamus nunc ad obligationes, quae ex delicto nascuntur, ueluti si quis furtum fecerit, bona rapuerit, damnum dederit, iniuriam commiserit. quarum omnium rerum uno genere consistit obligatio, cum ex contractu obligationes in IIII genera diducantur, sicut supra exposuimus.

${ }^{72}$ D. 44,7,4 (Gai. 3 res cott.): Ex maleficio nascuntur obligationes, veluti ex furto, ex damno, ex rapina, ex iniuria. quae omnia unius generis sunt: nam hae re tantum consistunt, id est ipso maleficio, cum alioquin ex contractu obligationes non tantum re consistant, sed etiam verbis et consensu.

73 Harke, 2013, p. 38.

${ }^{74}$ I. 3,13,2: (...) Prius est, ut de his quae ex contractu sunt dispiciamus. Harum aeque quattuor species sunt: aut enim re contrabuntur aut verbis aut litteris aut consensu. de quibus singulis dispiciamus. 
si antes las obligationes re, verbis, litteris y consensu contractae eran fenómenos esencialmente distintos (géneros), de ahora en adelante serán especies de un mismo género, especies del contrato-convención. De esta manera, lo que para los clásicos fueron las distintas hipótesis de causae obligationum, de causas de obligación, cada cual distinta e independiente, para los bizantinos ya no serán más que las formas en las que puede manifestarse el consensus que está a la base de todo contrato, vale decir, el modo de perfeccionarlo. La tradición romanística de los siglos posteriores y, por cierto, nuestro Código Civil, son tributarios de esta corriente doctrinaria que, hoy, es indiscutida ${ }^{75}$. Pero esta es ya otra historia.

\section{CONCLUSIONES y PERSPECTIVAS}

Al comienzo decíamos que el sistema de las Pandectas no es el sistema de la ciencia pandectística. Ahora podemos añadir: la estructura del derecho contractual romano no es la nuestra, y no tendría por qué serlo. El sintagma latino contrabere obligationem, según su uso por parte de la jurisprudencia clásica romana, atestiguado principalmente en las Instituciones de Gayo, no equivale a la moderna idea de perfeccionar un contrato. Los clásicos razonaban sobre la base de las causas de las obligaciones (causae obligationum), no de los modos de perfeccionar un tipo contractual, como sí lo hará la tradición jurídica posterior, incluyendo entre sus frutos nuestro propio Código Civil.

Con el presente trabajo no pretendemos poner en entredicho la doctrina del contrato desarrollada durante siglos por la tradición jurídica europea-continental, ni mucho menos las bases del sistema contractual chileno. Nuestro objetivo es más modesto, pero no por ello inútil: llamar la atención respecto de posibles interpretaciones descontextualizadas de las fuentes histórico-jurídicas, que conducen de una u otra manera a construcciones anacrónicas de la experiencia jurídica romana y, a la larga, a una falsa representación del desarrollo histórico de nuestro derecho privado. Y es que siguiendo la exhortación de Wieacker, la dignidad de la tarea cognoscitiva del historiador del derecho no radica tanto en fundamentar reglas o principios jurídicos vigentes ni, por tanto, en ser útil para el presente, sino más bien en la intrínseca historicidad de nuestra propia existencia ${ }^{76}$. Pero además, un comparativismo histórico o, si se quiere, una historia jurídica comparada consciente de sus límites, pero también de sus potencialidades, nos ayuda a comprender más adecuadamente los contextos que han dado lugar a distintas experiencias jurídicas y, con ello, el sistema dentro del que operamos, con mayor profundidad y espíritu crítico $^{77}$. En definitiva, y aunque parezca un juego de palabras, el estudio de los dogmas jurídicos, la historia dogmática (la Dogmengeschichte), puede llegar a ser nuestra principal

${ }^{75}$ Para el desarrollo de la moderna noción de contrato-convención, véase por ejemplo NANZ, 1985, pp. 5 ss.; Zimmermann, 1996, pp. 546 ss.; Kegel, 2002, pp. 3 ss.; para sus raíces filosóficas GordLey, 1991, pp. 10 ss. Para la asimilación entre contrato y convención en el derecho chileno véase CarvaJAL, 2007, pp. 289 ss.

76 Wieacker, 1967, p. 15. En el mismo sentido Caroni, 2014, p. 74 (n. 52).

77 Al respecto, véase Pinlajamäki, 2014, pp. 121 ss. 
defensa contra eventuales dogmatismos, con el fin de no violentar el genuino sentido de las fuentes que inspiraron la formación del derecho vigente. El estudio del significado del sintagma contrabere obligationem en el derecho romano clásico es un ejemplo de ello.

\section{BIBLIOGRAFÍA}

Avenarius, Martin, 2005: Der pseudo-ulpianische liber singularis regularum. Entstehung, Eigenart und Überlieferung einer hochklassischen Juristenschrift, Göttingen, Wallstein.

Avenarius, Martin, 2008: "Tradition, Vorverständnis und Wirkungsgeschichte der Quellen. Vom Einfluß der geisteswissenschaftlichen Hermeneutik auf das romanistische Verstehen”, en el mismo (editor), Hermeneutik der Quellentexte des Römischen Rechts, Baden-Baden, Nomos, pp. 9-29.

BETTI, Emilio, 1912: "Sul significato di 'contrahere' in Gaio e sulla non-classicità della denominazione 'quasi ex contractu obligatio'”, Bullettino dell' Istituto di Diritto Romano 'Vittorio Scialoja', volumen XXV, pp. 65-88.

BetTi, Emilio, 1915: "Sul valore dogmatico della categoria 'contrahere' in giuristi proculiani e sabiniani”, Bullettino dell' Istituto di Diritto Romano 'Vittorio Scialoja', volumen XXVIII, pp. 3-96.

BETTI, Emilio, 1955: La struttura dell'obbligazione romana ed il problema della sua genesi (2a edición), Milano, Giuffrè.

Brasiello, Ugo, 1930: "Obligatio re contracta", en Studi in onore di Pietro Bonfante II, Milano, Giuffrè, pp. 539-587.

Brasiello, Ugo, 1944: "In tema di categorie contrattuali", Studia et Documenta Historiae et Iuris, volumen X, pp. 101-149.

Bretone, Mario, 1982: Tecniche e ideologie dei giuristi romani (2 ${ }^{\mathrm{a}}$ edición), Napoli, Edizioni Scientifiche Italiane.

BrutTi, Massimo, 1979: "Storiografia e critica del sistema pandettistico", en Quaderni Fiorentini per la Storia del Pensiero Giuridico Moderno, volumen VIII, pp. 317-360.

Cannata, Carlo Augusto, 2008: Materiali per un corso di fondamenti del diritto europeo II, Torino, Giappichelli.

Caroni, Pio, 2014: La soledad del historiador del derecho. Apuntes sobre la conveniencia de una disciplina diferente (trad. de Mora Cañada, A., y Martínez Neira, M.), Madrid, Universidad Carlos III de Madrid.

Carvajal, Patricio Ignacio, 2007: “Arts. 1437 y 1438 del Código Civil. 'Contrato' y 'convención' como sinónimos en materia de fuentes de las obligaciones”, Revista Chilena de Derecho, volumen XXXIV, $\mathrm{N}^{\circ} 2$, pp. 289-302.

Casinos Mora, Francisco Javier, 2002: “Nueve siglos de romanismo jurídico”, Rivista di Diritto Romano, volumen II, pp. 351-399.

Coma Fort, José María, 1996: El derecho de obligaciones en las res cottidianae, Madrid, Fundación Seminario de Derecho Romano Urcisino Álvarez.

Crifò, Giuliano, 1995: "Some Reflections on History and Dogma as Jurists' Tools”, en Cairns y Robinson (editores), Critical Studies in Ancient Law, Comparative Law and Legal History. Essays in Honour of Alan Watson, Oxford/Portland, Hart, pp. 37-44.

Cuena Boy, Francisco, 1998: Sistema jurídico y derecho romano. La idea de sistema jurídico y su proyección en la experiencia jurídica romana, Santander, Universidad de Cantabria.

Dalla Massara, Tommaso, 2004: Alle origini della causa del contratto. Elaborazione di un concetto nella giurisprudenza classica, Padova, Cedam. 
David, Martin y Nelson, H.L.W., 1954: Gai Institutionum Commentarii IV mit philologischem Kommentar, Leiden, Brill.

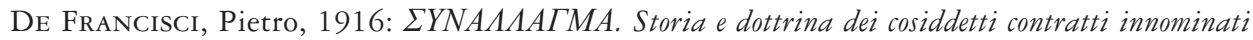
II, Pavia, Mattei.

De Visscher, Fernand, 1931: “Les origines de l'obligation 'ex delicto'”, en Études de droit romain, Paris, Sirey, pp. 336-386.

Falcone, Giuseppe, 2011: "Sistematiche gaiane e definizione di obligatio", en CapogrossiColognesi y Cursi (editores), Obligatio-obbligazione. Un confronto interdisciplinare (Atti del Convegno di Roma 23-24 settembre 2010), Napoli, Jovene, pp. 17-51.

Garofalo, Luigi, 2006: "Contratto, obbligazione e convenzione in Sesto Pedio", en Burdese (editor), Le dottrine del contratto nella giurisprudenza romana, Padova, Cedam, pp. 337-378.

GiUfFrè, Vincenzo, 2016: “La definizione di 'obligatio' nelle 'Gai Institutiones'. Un'isola che non c'è?", Iura: rivista internazionale di diritto romano e antico, volumen LXIV, pp. 101-126.

Gordley, James, 1991: The Philosophical Origins of Modern Contract Doctrine, Oxford, Oxford University Press.

Gordley, James, 2006: "Comparative Law and Legal History", en Reimann y Zimmermann (editores), The Oxford Handbook of Comparative Law, Oxford, Oxford University Press, pp. $753-773$.

Grosso, Giuseppe, 1963: Il sistema romano dei contratti (3a edición), Torino, Giappichelli.

Gröschler, Peter, 1997: Die tabellae-Urkunden aus den pompejanischen und herkulanensischen Urkundenfunden, Berlin, Duncker \& Humblot.

GuZmán Brito, Alejandro, 2005: Acto, negocio, contrato y causa en la tradición del derecho europeo e iberoamericano, Cizur Menor, Aranzadi.

HARKe, Jan Dirk, 2013: Studien zu Vertrag und Eigentumserwerb im römischen Recht, Berlin, Duncker \& Humblot.

Harke, Jan Dirk, 2016: Römisches Recht. Von der klassischen Zeit bis zu den modernen Kodifikationen ( $2^{\mathrm{a}}$ edición), München, C.H. Beck.

Heumann, Hermann Gottlieb y Seckel, Emil, 1926: Handlexikon zu den Quellen des römischen Rechts ( $9^{a}$ edición), Jena, Verlag von Gustav Fischer.

Hoetink, Hendrik Richard, 1955: "Über anachronistische Begriffsbildung in der Rechtsgeschichte”, Zeitschrift der Savigny Stiftung für Rechtsgeschichte, romanistische Abteilung, volumen LXXII, pp. 39-53.

Jörs, Paul; Kunkel, Wolfgang y Wenger, Leopold, 1949: Römisches Recht (3ª edición), Berlin/ Heidelberg, Springer.

Kaser, Max, 1949: Das altrömische Ius. Studien zur Rechtsvorstellung und Rechtsgeschichte der Römer, Göttingen, Vanderhoeck \& Ruprecht.

Kaser, Max, 1961: "Das Geld im römischen Sachenrecht", Tijdschrift voor Rechtsgeschiedenis, volumen XXIX, pp. 169-229.

Kaser, Max, 1971: Das Römische Privatrecht I (2a edición), München, C.H. Beck.

Kegel, Gerhard, 2002: Vertrag und Delikt, München, Heymanns.

Kollmann, Andreas, 1996: Begriffs- und Problemgeschichte des Verbältnisses von formellem und materiellem Recht, Berlin, Duncker \& Humblot.

Labruna, Luigi, 1962: Rescriptum Divi Pii. Gli atti del pupillo sine tutoris auctoritate, Napoli, Jovene.

Lauria, Mario, 1938: "Contractus, delictum, obligatio (a proposito di recenti studi)", Studia et Documenta Historiae et Iuris, volumen IV, pp. 163-192.

LoNGo, Carlo, 1933: Corso di diritto romano. Il mutuo, Milano, Giuffrè.

LöHNig, Martin, 2014: "Comparative Law and Legal History: A Few Words about Comparative Legal History”, en Adams y Heirbaut (editores), The Method and Culture of Comparative Law. Essays in Honour of Mark Van Hoecke, Oxford/Portland, Hart, pp. 113-120. 
Martini, Remo, 1991: "Il mito del consenso nella dottrina del contratto", Iura: rivista internazionale di diritto romano e antico, volumen XLII, pp. 97-109.

Melillo, Generoso, 1994: Contrahere, pacisci, transigere. Contributi allo studio del negozio bilaterale romano, Napoli, Liguori.

NanZ, Klaus Peter, 1985: Die Entstehung des allgemeinen Vertragsbegriffs im 16. bis 18. Jabrhundert, München, Schweitzer.

NöRR, Knut Wolfgang, 1994: "Das römische Recht zwischen Technik und Substanz: Bemerkungen zu seiner Rolle am Ende des 20. Jahrhunderts", Zeitschrift für Europäisches Privatrecht, volumen II, pp. 67-76.

Orestano, Riccardo, 1959: "Obligationes e dialettica”, en Droits de l'antiquité et sociologie juridique. Mélanges Henri Lévy-Brubl, Paris, Sirey, pp. 445-458.

PARICIO, Javier, 1994: "Las fuentes de las obligaciones en la tradición gayano-justinianea", en el mismo (editor), Derecho romano de obligaciones. Homenaje al profesor José Luis Murga Gener, Madrid, Centro de Estudios Ramón Areces, pp. 49-61.

PARICIO, Javier, 1997: "Sull'idea di contratto in Gaio", en Vacca (editora), Causa e contratto nella prospettiva storico-comparatistica, Torino, Giappichelli, pp. 151-160.

Paricio, Javier, 2008: Contrato. La formación de un concepto, Cizur Menor, Civitas, 2008.

Pernice, Alfred, 1888: "Parerga III. Zur Vertragslehre der römischen Juristen”, Zeitschrift der Savigny Stiftung für Rechtsgeschichte, romanistische Abteilung, volumen IX, pp. 195-260.

Perozzi, Silvio, 1898: "Il contratto consensuale classico", en Nani, Pampaloni y Fusinato (editores), Studi giuridici dedicati e offerti a Francesco Schupfer del XXXV anno del suo insegnamento, Roma, Bretschneider, pp. 163-199.

PihlajamäKi, Heikki, 2014: "Comparative Contexts in Legal History: Are We All Comparatists Now?", en Adams y Heirbaut (editores), The Method and Culture of Comparative Law. Essays in Honour of Mark Van Hoecke, Oxford/Portland, Hart, pp. 121-132.

Riccoвono, Salvatore, 1930: "La formazione della teoria generale del contractus nel periodo della giurisprudenza classica", en Studi in onore die Pietro Bonfante nel XL anno d'insegnamento I, Milano, Giuffrè, pp. 123-173.

SARgenti, Manlio, 1988: "Svolgimento dell'idea di contratto nel pensiero giuridico romano", Iura: rivista internazionale di diritto romano e antico, volumen XXXIX, pp. 24-74.

SChiavone, Aldo, 1971: Studi sulle logiche dei giuristi romani. Nova negotia e transactio da Labeone a Ulpiano, Napoli, Jovene.

Schulz, Fritz, 1951: Classical Roman Law, Oxford, Oxford University Press.

SCHWARZ, Andreas, 1921: "Zur Entstehung des modernen Pandektensystems", Zeitschrift der Savigny Stiftung für Rechtsgeschichte, romanistische Abteilung, volumen XLII, pp. 578-610.

SEgrè, Gino, 1952: "Sulla classificazione delle cause delle obligationes nelle Istituzioni di Gaio", en Scritti vari di diritto romano, Torino, Giappichelli, pp. 433-442.

Talamanca, Mario, 1979: "Obbligazioni (diritto romano)", Enciclopedia del Diritto, volumen XXIX, pp. 1-78.

VACCA, Letizia, 2006: Metodo casistico e sistema prudenziale, Padova, Cedam.

VIARD, Paul-Émile, 1939: La 'mutui datio'. Contribution à l'bistoire du fondement des obligations à Rome. Première partie, Paris, Sirey.

VocI, Pasquale, 1946: La dottrina romana del contratto, Milano, Giuffrè.

Watson, Alan, 1974: Legal Transplants. An Approach to Comparative Law, Edinburgh, Scottish Academic Press.

Watson, Alan, 1991: Roman Law and Comparative Law, Athens, The University of Georgia Press.

Wegmann Stockebrand, Adolfo, 2017a: Obligatio re contracta. Ein Beitrag zur sogenannten Kategorie der Realverträge im römischen Recht, Tübingen, Mohr Siebeck. 
Wegmann Stockebrand, Adolfo, 2017b: "En torno a la noción de sistema jurídico y a la construcción de una categoría general del contrato en el derecho romano", Revista Chilena de Derecho, volumen XLIV, No 2, pp. 323-346.

Wieacker, Franz, 1967: Privatrechtsgeschichte der Neuzeit unter besonderer Berïcksichtigung der deutschen Entwicklung, Göttingen, Vanderhoeck \& Ruprecht.

WoŁodkiewicz, Witold, 1978: "Contrahere-contractum-contractus dans le droit romain classique”, en Kupiszewski y el mismo (editores), Le droit romain et sa reception en Europe, Warszawa, Fac. de Droit et d'Administration, pp. 295-308.

Wunner, Sven Erik, 1964: Contractus. Sein Wortgebrauch und Willensgehalt im klassischen römischen Recht, Köln/Graz, Böhlau.

Zannini, Pierluigi, 1976: Studi sulla tutela mulierum I. Profili funzionali, Torino, Giappichelli.

Zimmermann, Reinhard, 1996: The Law of Obligations. Roman Foundations of the Civilian Tradition, Cape Town, Oxford University Press, 1992, reimp. Oxford, 1996. 